\title{
BANTUAN TEKNIS PERENCANAAN ATAP BETON DAN RENCANA ANGGARAN BIAYA RENOVASI MUSHOLLA DARUL ULUM DI RT.03 RW.06 KELURAHAN MERJOSARI KECAMATAN LOWOKWARU MALANG
}

\author{
Sugiharti ${ }^{1}$, Sitti Safiatus Riskijah ${ }^{2}$, Maryono ${ }^{3}$, Susapto ${ }^{4}$, Suselo Utoyo ${ }^{5}$ \\ $1,2,3,4,5$ Dosen Jurusan Teknik Sipil Politeknik Negeri Malang \\ ${ }^{1}$ sugihartisasmoko@gmail.com,
}

\begin{abstract}
Abstrak - Musholla Darul Ulum merupakan salah satu tempat ibadah masyarakat warga RT.03 RW.06 Kelurahan Merjosari Malang. Kondisi atap saat ini banyak yang bocor jika terjadi hujan, disebabkan karena rangka atap dan penutup atap rusak. Untuk meningkatkan kenyamanan masyarakat RT.03 dalam beribadah maka warga berencana untuk memperbaiki atap musholla. Perbaikan atap dilakukan dengan cara mengganti atap lama menjadi atap beton. Untuk itu Ketua takmir musholla sebagai wakil dari warga RT.03 meminta bantuan tim PKM Politeknik Negeri Malang untuk memberikan bantuan teknis perencanaan atap beton musholla berikut rencana anggaran biayanya agar warga setempat dapat menyiapkan semua kebutuhan untuk perbaikan atap tersebut. Hasil yang didapat dari kegiatan PKM ini yaitu perencanaan plat atap beton menggunakan mutu beton $f_{c}$ ' $25 \mathrm{Mpa}$, mutu baja fy $250 \mathrm{Mpa}$, tebal plat beton $15 \mathrm{~mm}$ dengan selimut beton $20 \mathrm{~mm}$, menggunakan tulangan diameter $10 \mathrm{~mm}$ jarak 200 $\mathrm{mm}$, dan perencanaan balok dengan dimensi balok lebar $20 \mathrm{~mm}$ dan tinggi $40 \mathrm{~mm}$ dengan selimut beton $30 \mathrm{~mm}$, menggunakan mutu beton $\mathrm{fc}^{\prime} 250 \mathrm{Mpa}$, mutu baja polos fy 240 Mpa untuk tulangan geser dengan diameter $8 \mathrm{~mm}$ dan jarak $170 \mathrm{~mm}$, dan mutu baja deform fy 400 Mpa untuk tulangan lentur sejumlah 2 tulangan atas dan 2 tulangan bawah 2D13. Metode pelaksanaan pekerjaan atap musholla menggunakan beton yang dibuat dengan menggunakan mesin mollen kapasitas $1 \mathrm{m3}$, pengangkutan beton segar menggunakan mesin katrol kapasitas 1 m3, penuangan beton menggunakan talang yang dibantu pekerja untuk mendistribusikan dan meratakan permukaan beton, pemadatan beton menggunakan vibrator, dan perawatan beton setelah pengecoran dengan cara menutupnya dengan terpal dan sesekali disemprot dengan air. Rencana anggaran biaya renovasi atap Musholla Darul Ulum sejumlah Rp 85.517.000,00 (Delapan puluh lima juta lima ratus tujuh belas ribu rupiah).
\end{abstract}

Kata kunci: perencanaan atap, beton bertulang, rencana anggaran biaya

\section{PENDAHULUAN}

\subsection{Latar Belakang}

Wilayah RT.03 RW.06 Kelurahan Merjosari Kecamatan Lowokwaru Malang dihuni oleh penduduk yang berjumlah kurang lebih 80 kepala keluarga yang semuanya muslim. Terdapat satu musholla di wilayah ini sebagai tempat beribadah bersama. Saat ini kondisi musholla ini mengalami kerusakan di bagian atapnya sehingga mengganggu masyarakat yang beribadah. Melihat kondisi seperti ini, mayarakat RT.03 berinisiatif untuk mengganti atap menjadi atap beton dengan swadana masyarakat setempat.

Untuk merealisasikan inisiatifnya, maka Ketua Takmir musholla setempat meminta bantuan Tim Pengabdian Kepada Masyarakat (PKM) Politeknik Negeri Malang untuk memberikan Bantuan Teknis Perencanaan Atap Beton dan Rencana Anggaran Biaya Renovasi Musholla Darul Ulum di RT.03 RW.06 Kelurahan Merjosari Kecamatan Lowokwaru Malang.

Berdasarkan analisis situasi di atas, maka tujuan kegiatan Pengabdian Kepada Masyarakat ini adalah merencanaan dimensi atap beton Musholla Darul Ulum yang terdiri dari plat dan balok, menyusun metode pelaksanaan, dan merencanakan anggaran biaya yang dibutuhkan untuk perbaikan atap Musholla Darul Ulum.

Dalam perencanaan dan proses pelaksanaan pembangunan gedung mengacu pada peraturan dan standar kontruksi Indonesia, yaitu:

- Pedoman perencanaan beban minimum untuk perancangan bangunan gedung dan struktur lain SNI 1727-2002

- Pedoman tata cara perencanaan ketahanan gempa untuk struktur bangunan gedung dan non gedung SNI 1726-2012

- Pedoman tata cara perencanaan beton SNI BETON 03-2847-2002

- Pedoman perencanaan pembebanan indonesia untuk gedung (PPIUG 1983)

- Pedoman-pedoman lain yang menunjang dan bermanfaat.

\section{ANALISA PEMBEBANAN}

Mutu beton dalam perencanaan pembangunan gedung harus diperhatikan agar tidak kurang dari persyaratan minimum untuk perencanaan bangunan sesuai standar SNI BETON 03-2847-2002. Dimana untuk beton struktur, fc' tidak boleh kurang dari 17 MPa. Sedangkan Nilai maksimum fc' tidak dibatasi kecuali bilamana dibatasi oleh ketentuan standar tertentu. Standar ini melengkapi peraturan bangunan gedung secara umum dan harus mengatur dalam semua hal yang berkaitan dengan desain, kontruksi beton struktur, kecuali bilamana standar ini bertentangan dengan persyaratan secara umum yang di adopsi secara ilegal dan tidak sesuai dengan standar SNI Beton 03-2847-2002.

Pada desain gedung menurut peraturan perencanaan pembebanan tahun 1983 untuk rumah dan gedung harus direncanakan kekuatannya terhadap 
pembebanan yang di akibatkan oleh Beban Hidup (L), Beban Mati (M), Beban Angin (W), Beban Gempa (E), dan Beban Khusus (K). Secara garis besar SNI 1727-2002 dengan pedoman peraturan perencanaan pembebanan indonesia tahun 1983 memiliki isi dan maksud yang sama, yaitu memperhitungkan kekuatan bangunan dengan pembebanan yang akan dianalisa, hanya pada SNI 1727-2013 lebih spesifik dan detail, tapi pada umumnya pembebanan yang di analisis adalah sebagai berikut:

\subsection{Beban Mati (D)}

Beban mati adalah berat dari semua bagian suatu gedung yang bersifat tetap, termasuk segala unsur tambahan, penyelesaian-penyelesaian, mesinmesin serta peralatan tetap yang merupakan bagian tak terpisahkan dari gedung itu. Untuk merencanakan gedung atau rumah tinggal, beban mati yang terdiri dari berat itu sendiri bangunan dan komponen gedung adalah :

1. Bahan bangunan: a. Beton bertulang $=2400$ $\mathrm{kg} / \mathrm{m} 3$; b. Pasir $=1800 \mathrm{~kg} / \mathrm{m} 3$; c. Beton biasa $=$ $2200 \mathrm{~kg} / \mathrm{m} 3$

2. Komponen Gedung: a. Dinding bata $=20 \times 10 \times 7$ ; b. Plafon $=18 \mathrm{~kg} / \mathrm{m} 2$; c. Kaca = tebal 3-4 mm, berat $10 \mathrm{~kg} / \mathrm{m} 2$; d. Penutup lantai dengan dari keramik/granit dan beton (tanpa adukan) per $\mathrm{cm}$ tebal $=24 \mathrm{~kg} / \mathrm{m} 2$; Adukan semen per $\mathrm{cm}$ tebal $=$ $21 \mathrm{~kg} / \mathrm{m} 2$

\subsection{Beban Hidup (L)}

Beban hidup adalah semua bahan yang terjadi akibat penghuni atau pengguna suatu gedung, termasuk beban-beban lantai yang berasal dari barang-barang yang dapat berpindah, mesin-mesin serta peralatan yang merupakan bagian yang tidak terpisahkan dari gedung dan dapat diganti selama masa hidup dari gedung itu, sehingga mengakibatkan perubahan pembebanan lantai dan atap tersebut. Khususnya pada atap, beban hidup dapat termasuk beban yang berasal dari air hujan (PPIUG 1983).

\subsection{Beban angin $(\mathrm{W})$}

Beban Angin adalah semua baban yang bekerja pada gedung yang disebabkan oleh selisih dalam tekanan udara (PPUG 1983). Beban Angin di tentukan dengan mengangap adanya tekanan positif dan tekanan nagatif (hisapan), yang bekerja tegak lurus pada bidang yang ditinjau. Besarnya tekanan tiup dengan koefisien-koefisien angin. Tekan tiup harus diambil minimum $25 \mathrm{~kg} / \mathrm{m} 2$, kecuali untuk daerah di laut dan tepi laut sampai sejauh $5 \mathrm{~km}$ dari tepi pantai. Pada daerah tersebut tekanan hisap diambil minimum $40 \mathrm{~kg} / \mathrm{m} 2$. Sedangkan koefisien angin untuk gedung tertutup :

Dinding Vertikal : a. Di pihak angin $=+0,9$; b. Di belakang angin $=-0,4$.

Atap segitiga dengan sudut kemiringan $\alpha:$ a. Di pihak angin : $\alpha<65 \mathrm{o}=0,0 \alpha-0,4 ; 65 \mathrm{o}<\alpha<90 \mathrm{o}=+$ 0,9 ; b. Di belakng angin, untuk semua $\alpha=-0,4$.

\subsection{Beban Gempa (E)}

Beban gempa adalah semua beban statik ekivalen yang bekerja pada gedung atau bagian dari gedung yang merupakan pengaruh dari gerakan tanah akibat gempa tersebut :

Beban geser dasar gempa untuk analisis beban statik ekivalen, dengan rumus 1 :

$$
\mathrm{V}=\mathrm{C} \times \mathrm{I} \times \mathrm{K} \times \mathrm{Wt}
$$

Dimana : $\mathrm{V}=$ beban gempa horizontal $; \mathrm{C}=$ koefisien gempa ; I = faktor keutamaan; $\mathrm{K}=$ faktor jenis struktur; $\mathrm{Wt}=$ berat total bangunan

Waktu getar alami struktur T dalam detik untuk portal beton adalah :

$$
\mathrm{T}=0.06 \mathrm{H} 3 / 4
$$

Dimana : $\mathrm{T}=$ waktu getar $; \mathrm{H}=$ tinggi bangunan

\subsection{Beban Khusus (K)}

Beban khusus ialah semua beban yang bekerja pada gedung atau bagian gedung yang terjadi akibat selisih suhu, pengangkatan dan pemasangan, penurunan pondasi, susut, gaya-gaya tambahan yang berasal dari beban hidup seperti gaya rem yang berasal dari keran, gaya sentrifugal dan gaya dinamis yang berasal dari mesin-mesin, serta pengaruh-pengaruh khusus lainnya.

\subsection{Kekuatan Perlu}

Berdasarkan pedoman standar nasional SNI 1726-2012 tentang tata cara perencanaan ketahanan gempa untuk struktur bangunan gedung dan non gedung dapat dilihat dalam tabel 1 kombinasi beban tahun 2002 di bawah ini :

Tabel 1 Kombinasi Beban

\begin{tabular}{|l|l|l|}
\hline No & \multicolumn{1}{|c|}{ Beban } & \multicolumn{1}{c|}{ Kombinasi Beban } \\
\hline 1 & $D$ & $1,2 \mathrm{D}$ \\
\hline 2 & D,L,A,R & $1,2 \mathrm{D}-1,6 \mathrm{~L}+0.5$ (A atau $R$ ) \\
\hline 3 & $\mathrm{D}, \mathrm{L}, \mathrm{W}, \mathrm{A}, \mathrm{R}$ & $1,2 \mathrm{D}-1,0 \mathrm{~L}=1,6 \mathrm{~W}+0,5$ (A a:au $R$ ) \\
\hline 4 & $\mathrm{D}, \mathrm{W}$ & $0,9 \mathrm{D}=1,6 \mathrm{~W}$ \\
\hline 5 & $\mathrm{D}, \mathrm{L}, \mathrm{E}$ & $1,2 \mathrm{D}-1,0 \mathrm{~L}=1,0 \mathrm{E}$ \\
\hline 6 & $\mathrm{D}, \mathrm{E}$ & $0,9 \mathrm{D}=1,0 \mathrm{E}$ \\
\hline 7 & $\mathrm{D}, \mathrm{F}$ & $1,4(\mathrm{D}+\mathrm{F})$ \\
\hline 8 & $\mathrm{D}, \mathrm{T}, \mathrm{L}, \mathrm{A}, \mathrm{R}$ & $1,2(\mathrm{D}-\mathrm{T})+1,6 \mathrm{~L}+0,5(\mathrm{~A}$ atau $\mathrm{R})$ \\
\hline
\end{tabular}

Sumber: SNI 03-2847-2002

Keterangan: $\mathrm{D}=$ Beban mati $; \mathrm{L}=$ Beban hidup ; $\mathrm{W}=$ Beban angin ; $\mathrm{A}=$ Beban atap; $\mathrm{R}=$ Beban air hujan; $\mathrm{E}=$ Beban gempa $; \mathrm{T}=$ Pengaruh kombinasi suhu, rangkak, susut dan perbedaan penurunan ; $\mathrm{F}=$ Beban akibat berat dan tekanan fluida yang diketahui dengan baik

Sedangkan Berdasarkan pedoman standar nasional SNI 1726-2012 (C.9.2) tentang tata cara perencanaan ketahanan gempa untuk struktur bangunan gedung dan non gedung, kuat perlu diperhitungkan agar memenuhi syarat ketentuan dan layak pakai terhadap bermacam-macam beban, 
maka harus dipenuhi ketentuan dari faktor beban berikut :

1. Kekuatan perlu U untuk menahan beban mati D dan beban hidup $\mathrm{L}$ tidak boleh kurang dari : $\mathrm{U}=$ 1,4D + 1,7L (C.9-1)

2. Untuk struktur yang juga menahan beban angin (W), atau pengaruh beban gempa (E), U tidak boleh kurang dari yang terbesar dari persamaan (C.9-1),(C.9-2), dan (C.9-3) U = 0,75 $(1,4 \mathrm{D}+1,7 \mathrm{~L})+(1,0 \mathrm{~W}$ atau $1,0 \mathrm{E})(\mathrm{C} .9-2)$ Dan $\mathrm{U}$ $=0,9 \mathrm{D}+(1,0 \mathrm{~W}$ atau $1,0 \mathrm{E})(\mathrm{C} .9-3)$

Bila $\mathrm{W}$ didasarkan pada beban angin tingkat layan, 1,6W harus digunakan sebagai pengganti dari 1,0W dalam persamaan (C.9-2) dan (C.9-3). Bila E didasarkan pada pengaruh gempa tingkat layan, 1,4 E harus digunakan sebagai pengganti dari 1,0E dalam persamaan (C.9-2) dan (C.9-3) .

\section{ANALISA PERENCANAAN STRUKTUR}

\subsection{Perencanaan Pelat}

Pada struktur bangunan gedung pada umumnya tersusun atas beberapa komponen pelat atap, pelat lantai, balok dan kolom yang pada umumnya merupakan suatu kesatuan monolit pada sistem cetak ditempat atau terangkai seperti sistem pracetak. Pelat juga di gunakan sebagai atap, dinding, tangga, jembatan, atau dermaga di pelabuhan.

Pelat adalah struktur planar kaku yang terbuat dari material monolit dengan tinggi yang kecil dibandingkan dengan dimensi-dimensi lainnya. Untuk merencanakan pelat beton bertulang perlu mempertimbangkan faktor pembebanan dan ukuran serta syarat-syarat dari peraturan yang ada. Pada perencanaan ini digunakan tumpuan jepit penuh untuk mencegah pelat berotasi dan relatif sangat kaku terhadap momen puntir dan dalam pelaksanaan, pelat akan di cor bersamaan dengan balok.

\subsection{Rencana Anggaran Biaya (RAB)}

Rencana Anggaran Biaya (RAB) adalah suatu kegiatan perhitungan untuk mendapatkan jumlah biaya yang diperlukan untuk suatu kegiatan yang didasarkan atas informasi yang tersedia pada waktu itu. Biayabiaya yang terdapat dalam rencana anggaran biaya adalah sebagai berikut:

1. Biaya Langsung (Direct Cost)

Biaya langsung adalah Biaya untuk segala sesuatu yang akan menjadi komponen pen-nanent hasil akhir proyek (Soeharto, 1999). Biaya langsung terdiri dari: Biaya pengadaan material, Upah pekeda atau buruh, Biaya peralatan, dan Sub kontraktor

2. Biaya Tidak Langsung (Indirect Cost)

Yang termasuk di dalamnya adalah biaya kontingensi, overhead office, overhead site, pajak (PPN), keuntungan, dan biaya perizinan (Soeharto, 1999).

Dengan demikian biaya suatu pekerjaan dapat dihitung dengan rumus 2 .

Biaya Pekerjaan $=$ Kuantitas $\mathrm{x}$ HSP
Sedangkan Rencana Anggaran Biaya (RAB) dapat dihitung dengan rumus 3:

$$
\mathrm{RAB}=\sum(\text { Volume } \mathrm{x} \text { HSP })
$$

\section{SOLUSI DAN TARGET LUARAN}

Salah satu cara yang dapat dilakukan untuk mengganti atap musholla Darul Ulum yang bocor, diantaranya adalah mengganti atap yang baru yang terbuat dari beton bertulang. Kelebihan beton bertulang adalah kekuatannya, keawetannya, dan tahan air sehingga tidak bocor. Untuk mengganti atap yang baru tentunya diperlukan perencanaan baik rencana secara teknis maupun anggaran biayanya, sehingga diperlukan bantuan teknis perencanaan dari tim PKM Polinema sesuai permintaan pihak Takmir Musholla Darul Ulum.

Dalam pelaksanaan kegiatan PKM ini, tim PKM memberi masukkan-masukkan kepada masyarakat setempat khususnya ketua takmir Musholla Darul Ulum dalam melakukan perbaikan atap musholla. Bimbingan teknis yang ditawarkan berupa perencanaan dimensi atap beton bertulang, metode pelaksanaan dan rencana anggaran biaya perbaikan atap yang menggunakan dana dengan sumber swadana masyarakat setempat.

- Luaran dari kegiatan PKM ini adalah berupa:

- Hasil perencanaan dimensi atap beton bertulang

- Metode pelaksanaan perbaikan atap

- Rencana anggaran biaya perbaikan atap

- Draft jurnal ber-ISSN

\section{METODE PELAKSANAAN}

Kegiatan PKM ini berupa bimbingan teknis perencanaan renovasi atap musholla Darul Ulum di RT.03 RW.06 Kelurahan Merjosari. Waktu pelaksanaan kegiatan bimbingan teknis ini direncanakan selama 7 (tujuh) bulan terhitung sejak disetujuinya usulan. Adapun metode pelaksanaan kegiatan PKM ini yaitu:

- Meninjau lokasi musholla Darul Ulum

- Mengamati atap musholla yang rusak dan mengukur luasan atap

- Merencanakan dimensi atap

- Menyusun rencana anggaran biaya

- Melakukan diskusi dengan takmir musholla terkait metode pelaksanaan dan rencana anggaran biaya yang sudah disusun

\section{HASIL DAN LUARAN YANG DICAPAI}

\subsection{Kondisi Musholla Eksisting}

Dari peninjauan ini diketahui kondisi atap musholla menurut Ketua Takmir dan sebagian warga disana menyatakan bahwa kondisi atap rusak dan bocor ketika ada hujan. Kondisi musholla pada kondisi eksisting seperti pada Gambar 1. 

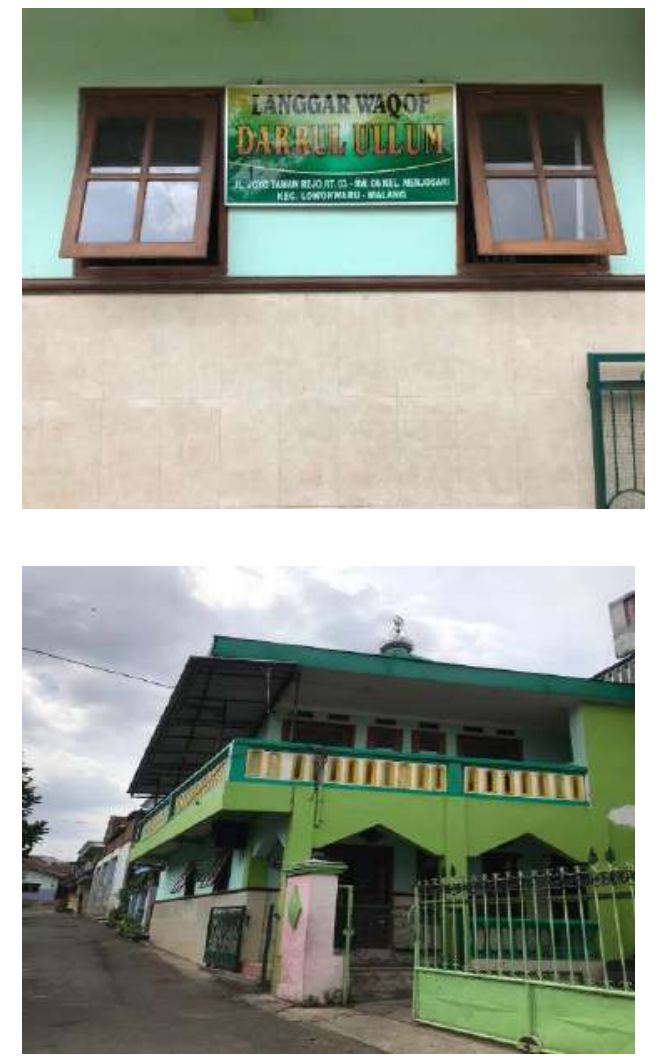

Gambar 1 Kondisi Musholla Eksisting

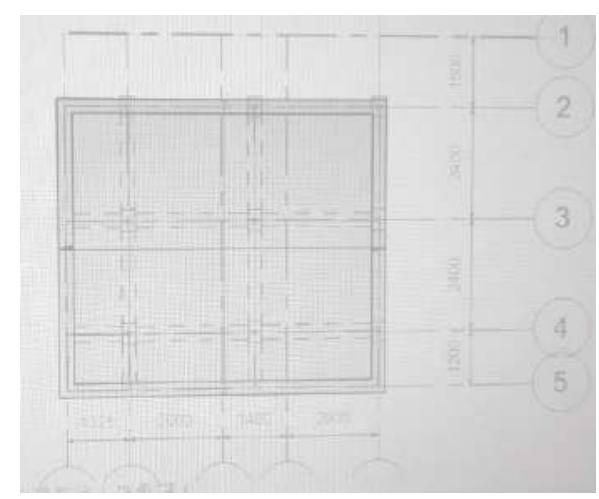

Gambar 2. Dimensi Atap Musholla

Data tentang dimensi atap musholla yang akan dibangun nantinya, dan diketahui luas musholla yaitu $40,35 \mathrm{~m}^{2}$. Rencananya plat atap dibuat dengan tebal 15 $\mathrm{cm}$ dan dimensi balok 20/40 $\mathrm{cm}$ karena diharapkan konstruksi atap mampu menerima beban jika musholla ini dipasang kubah. Denah rencana plat atap seperti pada gambar 2 .

\subsection{Perencanaan Atap Beton Musholla}

Perencanaan atap beton musholla ini terdiri dari perencanaan plat dan balok beton. Berdasarkan hasil perencanaan plat beton menggunakan mutu beton yang fc' $25 \mathrm{Mpa}$, mutu baja fy $250 \mathrm{Mpa}$, tebal plat beton 15 $\mathrm{mm}$ dengan selimut beton $20 \mathrm{~mm}$ menggunakan tulangan diameter $10 \mathrm{~mm}$ jarak $200 \mathrm{~mm}$, dan perencanaan balok dengan dimensi balok lebar $20 \mathrm{~mm}$ dan tinggi $40 \mathrm{~mm}$ dengan selimut beton $30 \mathrm{~mm}$ menggunakan mutu beton fc' $250 \mathrm{Mpa}$, mutu baja polos fy 240 Mpa untuk tulangan geser dengan diameter $8 \mathrm{~mm}$ dan jarak $170 \mathrm{~mm}$, dan mutu baja deform fy 400 Mpa untuk tulangan lentur sejumlah 2 tulangan atas dan 2 tulangan bawah 2D13. Gambar 4-7 menunjukkan hasil perencanaan dimensi dan penulangan plat dan balok atap musholla..

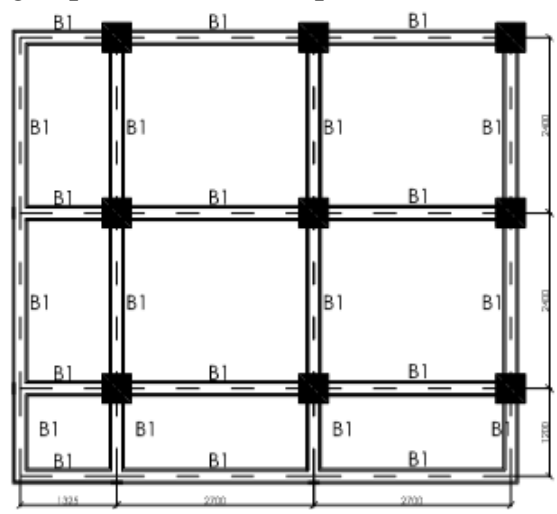

QDENAH BALOK

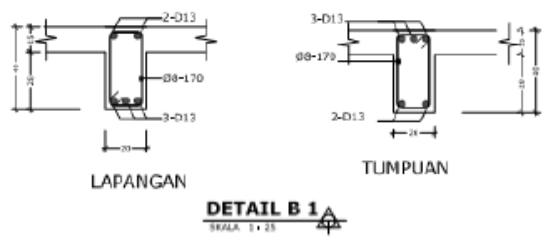

Gambar 4. Denah Balok dan Detail Balok

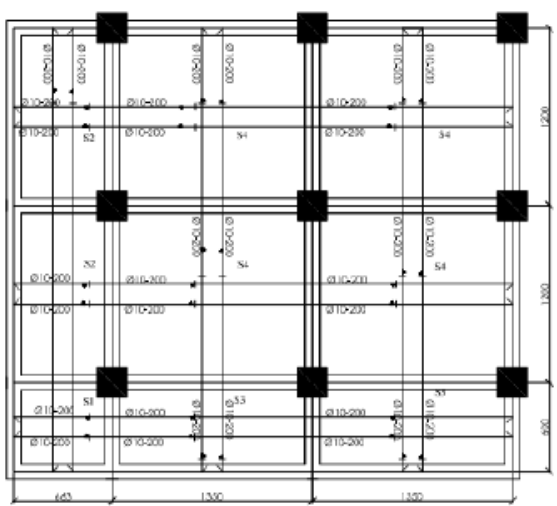

QDENAH PLAT

Gambar 5. Denah Plat

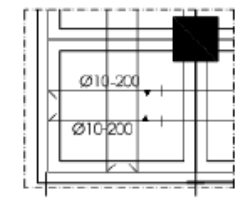

फ़ETAIL PLAT S1

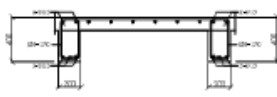

ФР РОT. I

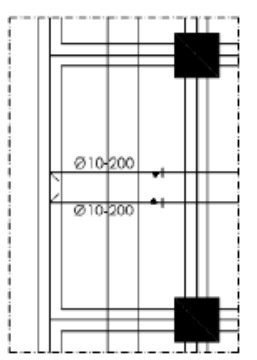

ФDDETAIL PLAT S2

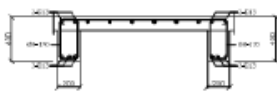

फि POT.I
Gambar 6. Detail Penulangan Plat S1 dan S2 


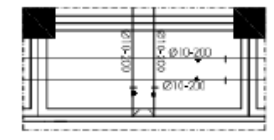

WDETAL PLAT \&3

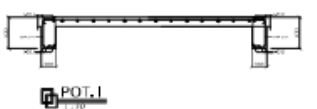

Gambar 7. Detail Penulangan Plat S3 dan S4

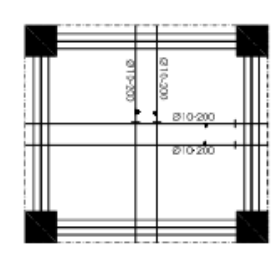

GDETALLFLT S4

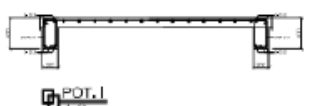

फएग.1
Metode pelaksanaan pekerjaan atap musholla yaitu bekisting menggunakan kayu, pekerjaan tulangan pabrikasi di lapangan, menggunakan beton fc' $25 \mathrm{Mpa}$ yang dibuat menggunakan mesin mollen kapasitas 1 $\mathrm{m} 3$, pengangkutan beton segar menggunakan mesin katrol kapasitas $1 \mathrm{~m} 3$, penuangan beton menggunakan talang yang dibantu pekerja untuk mendistribusikan dan meratakan permukaan beton, pemadatan mengguna-kan vibrator, dan perawatan beton setelah pengecoran dengan cara menutupnya dengan terpal dan sesekali disemprot dengan air. Pelaksanaan renovasi musholla ini seperti ditunjukkan pada gambar $8-9$ berikut:

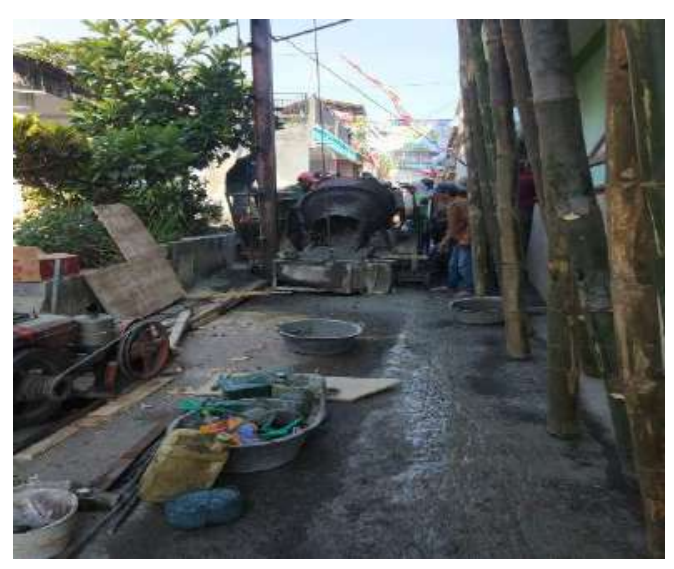

Gambar 8. Pekerjaan pengcoran plat dan balok

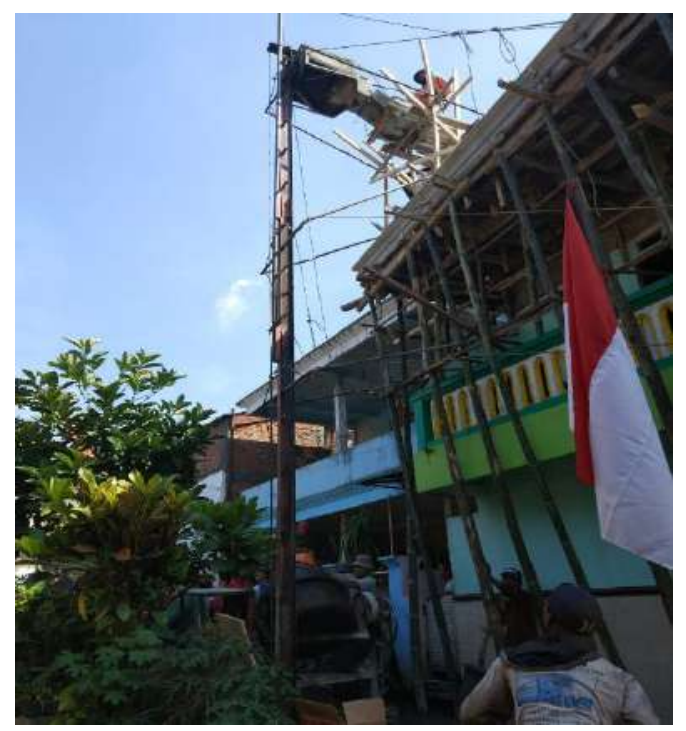

Gambar 9. Posisi Katrol saat Pengecoran Beton

\begin{tabular}{lccrr}
\hline $\begin{array}{c}\text { Item } \\
\text { Pekerjaan }\end{array}$ & Volume & Satuan & HSP (Rp) & \multicolumn{1}{c}{$\begin{array}{c}\text { Biaya } \\
\text { Pekerjaan (Rp) }\end{array}$} \\
\hline Plat & & & & $38.942 .370,012$ \\
Beton & 6,053 & $\mathrm{~m} 3$ & $1.784 .288,33$ & $10.799 .405,137$ \\
Pembesian & 371,675 & $\mathrm{~kg}$ & $13.789,83$ & $5.125 .338,847$ \\
Bekisting & 40,350 & $\mathrm{~m} 2$ & $570.449,22$ & $23.017 .626,027$ \\
Balok & & & & $43.574 .421,884$ \\
Beton & 4,072 & $\mathrm{~m} 3$ & $1.784 .288,33$ & $7.265 .622,093$ \\
Pembesian & 985,851 & $\mathrm{~kg}$ & $13.789,83$ & $13.594 .714,492$ \\
Bekisting & 50,900 & $\mathrm{~m} 2$ & $446.249,22$ & $22.714 .085,298$ \\
$\begin{array}{l}\text { Biaya 1 set mesin katrol, } \\
\text { molen, \& vibrator }\end{array}$ & $\mathrm{ls}$ & & $3.000 .000,000$ \\
\hline TOTAL & & & & $\mathbf{8 5 . 5 1 6 . 7 9 1 , 8 9 5}$ \\
\hline
\end{tabular}

Rencana anggaran biaya renovasi atap musholla Darul Ulum sejumlah Rp 85.517.000,00 (Delapan puluh lima juta lima ratus tujuh belas ribu rupiah).

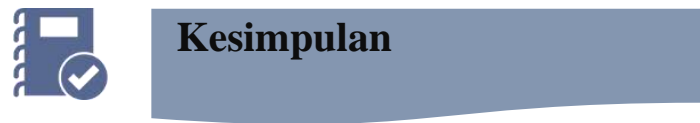

Berdasarkan hasil pelaksanaan kegiatan PKM ini dapat diambil kesimpulan sebagai berikut:

1. Berdasarkan hasil perencanaan plat beton menggunakan mutu beton fc' 25 Mpa, mutu baja fy $250 \mathrm{Mpa}$, tebal plat beton $15 \mathrm{~mm}$ dengan selimut beton $20 \mathrm{~mm}$ diperoleh tulangan polos diameter $10 \mathrm{~mm}$ jarak 200 $\mathrm{mm}$, dan perencanaan balok dengan dimensi balok lebar $20 \mathrm{~mm}$ dan tinggi $40 \mathrm{~mm}$ dengan selimut beton $30 \mathrm{~mm}$ menggunakan mutu beton fc' $250 \mathrm{Mpa}$, mutu baja polos fy 240 Mpa untuk tulangan geser dengan diameter 8 $\mathrm{mm}$ dan jarak $170 \mathrm{~mm}$, dan mutu baja deform fy 400 Mpa untuk tulangan lentur 
sejumlah 2 tulangan atas dan 2 tulangan bawah 2D13.

2. Metode pelaksanaan pekerjaan atap musholla yaitu bekisting menggunakan kayu, pekerjaan tulangan pabrikasi di lapangan, dan pekerjaan beton dengan cara beton dibuat menggunakan mesin mollen kapasitas $1 \mathrm{~m} 3$, pengangkutan beton segar menggunakan mesin katrol kapasitas $1 \mathrm{~m} 3$, penuangan beton menggunakan talang yang dibantu pekerja untuk mendistribusikan dan meratakan permukaan beton, pemadatan menggunakan vibrator, dan perawatan beton setelah pengecoran dengan cara menutupnya dengan terpal dan sesekali disemprot dengan air.

3. Rencana anggaran biaya renovasi atap musholla Darul Ulum sejumlah $\mathrm{Rp}$ 85.517.000,00 (Delapan puluh lima juta lima ratus tujuh belas ribu rupiah).

\section{Daftar Rujukan}

Pedoman perencanaan beban minimum untuk perancangan bangunan gedung dan struktur lain SNI 1727-2002.

Pedoman tata cara perencanaan ketahanan gempa untuk struktur bangunan gedung dan non gedung SNI 1726-2012

Pedoman Tata Cara Perencanaan Beton SNI BETON 03-2847-2002

Pedoman Perencanaan Pembebanan Indonesia Untuk Gedung (PPIUG 1983)

Peraturan Beton Indonesia (PBI - 1971)

Soeharto, Iman. 1999. Manajemen Proyek: Dari Konseptual Sampai Operasional. Jakarta: Erlangga.

Peraturan Menteri Pekerjaan Umum dan Perumahan Rakyat Nomor 28/PRT/M/2016 tentang Analisa Harga Satuan Pekerjaan Umum. 2016. JDIH Kementerian PUPR.

SNI Standar Nasional Indonesia 2847:2013. Persyaratan Beton structural untuk Bangunan Gedung. ICS 91.080.40. BSN 2013. Jakarta. 